\title{
Ventricular inversion without transposition of the great vessels in situs inversus
}

\author{
Jorge Espino-Vela, María V. de la Cruz, Luis Muñoz-Castellanos, Leandro Plaza, \\ and Fause Attie \\ From the Department of Paediatric Cardiology and the Department of Embryology, Instituto \\ Nacional de Cardiología, Av. Cuauhtémoc 300, México 7, D.F. México
}

$A$ classification of one type of congenital malformation previously reported (de la Cruz et al., 1967) is based on the integration of an embryological theory for ventricular inversions with the embryological concepts of trunco-conal malformations (de la Cruz and da Rocha, 1956). In that classification we consider that in each situs, either solitus or inversus ventricular inversions may be associated with: (a) normally arranged great vessels (not transposed); (b) transposition of the great vessels; (c) persistent truncus arteriosus. The patients had ventricular inversion without transposition of the great vessels in situs inversus.

The correct anatomical diagnosis was not foreseen but the physiopathological diagnosis was correct: pulmonary ischaemia associated with septal defects. In one case these facts were substantiated by catheterization and by angiocardiographic findings which led us to advise surgery. Haemodynamically isolated inversion of the ventricles is as severe a malformation as complete (not corrected) transposition of the great vessels. However, an operation of the anastomotic type between a systemic vessel and the narrow pulmonary artery seemed justified in these cases, as a means to convey more blood to the lungs and improve the saturation of the arterial blood. It was unsuccessfully carried out in one patient.

The anatomical, radiological, and electrocardiographic features which might aid in the diagnosis are analysed.

The term 'corrected transposition' of the great arteries, implies two anatomical concepts: transposition of the great arteries and inversion of the ventricular chambers. Therefore, the designation does not emphasize what appears to be the most salient feature of such an entity, that is ventricular inversion (Walmsley, I931; Abbott, 1936; Liebow and McFarland, 194I; de la Cruz et al., I959; de la Cruz, Polansky, and NavarroLópez, 1962; Van Praagh et al., 1964). For this reason, a new classification and nomenclature was proposed by us in a recent paper (de la Cruz et al., 1967). Ventricular inversion is the basis of the classification, either for patients with situs solitus or with situs inversus; it may be associated with, (a) vessels which cross each other in space with an anteriorly placed pulmonary artery, i.e. without transposition of the great arteries (Van Praagh and Van Praagh, I966); (b) parallel vessels with an anteriorly placed aorta, i.e. transposition of the great arteries; and (c) persistent common truncus (Anselmi et al., 1963).

Received 22 August 1969.
The purpose of this paper is the analysis of two cases of ventricular inversion without transposition of the great arteries, apparently the most uncommon of the three possibilities described. Both were cases of situs inversus.

\section{Case reports}

Case I A 19-year-old girl, cyanotic from birth, suffered repeated hypoxic spells from 3 months until the age of 8 years. She had dyspnoea on moderate exertion and greatly diminished physical endurance. Physical examination disclosed a frail underdeveloped young woman with arachnodactyly and an asymmetrical chest wall. The cardiac apical impulse was felt on the 4th right intercostal space. Auscultation of the heart disclosed a soft grade 2/4 systolic murmur in the midpraecordial area. The second 'pulmonary' sound was single and reinforced. Blood pressure was $120 / 70 \mathrm{~mm}$. Hg. The liver was percussed on the left side.

The chest $x$-ray (Fig. Ia) disclosed a slightly enlarged heart with a wide pedicle. It had a prominent vascular segment on the right side, and another prominent segment on the left cardiac border. The pulmonary circulation was decreased. The ventricle on the right was thought to be enlarged. The position of the cardiac apex was not established clearly. 
FIG. I Case I. Mirror-image dextrocardia and ventricular inversion without transposition of the great vessels. (a) Chest film. The apex is not clearly seen on either side. Notice the slight prominence of the aorta to the right and the prominence of what appears to be the 'pulmonary' segment on the left border of the heart. The vascularity of the lungs is slightly decreased. (b) Electrocardiogram which shows a negative $P$ wave in lead I. Notice that VR is a predominantly positive complex, which would be unusual for a situs inversus but not for the right-sided right ventricle which this case had (ventricular inversion). The sequence of the ventricular complexes in the praecordial leads is that usually expected for normally placed ventricles in the presence of right ventricular hypertrophy. (c) Diagrammatic representation showing the spatial relation of the great vessels, the cardiac chambers, the direction of the apex, and the position of the liver. $P A$, pulmonary artery; Ao, aorta; $L A$, anatomically left atrium; $R V$, anatomically right ventricle; $R A$, anatomical right atrium; $L V$, anatomical left ventricle. $(d)$ External aspect of the heart, of the great vessels and of the liver. $P A$, narrow pulmonary artery; Ao aorta.

a
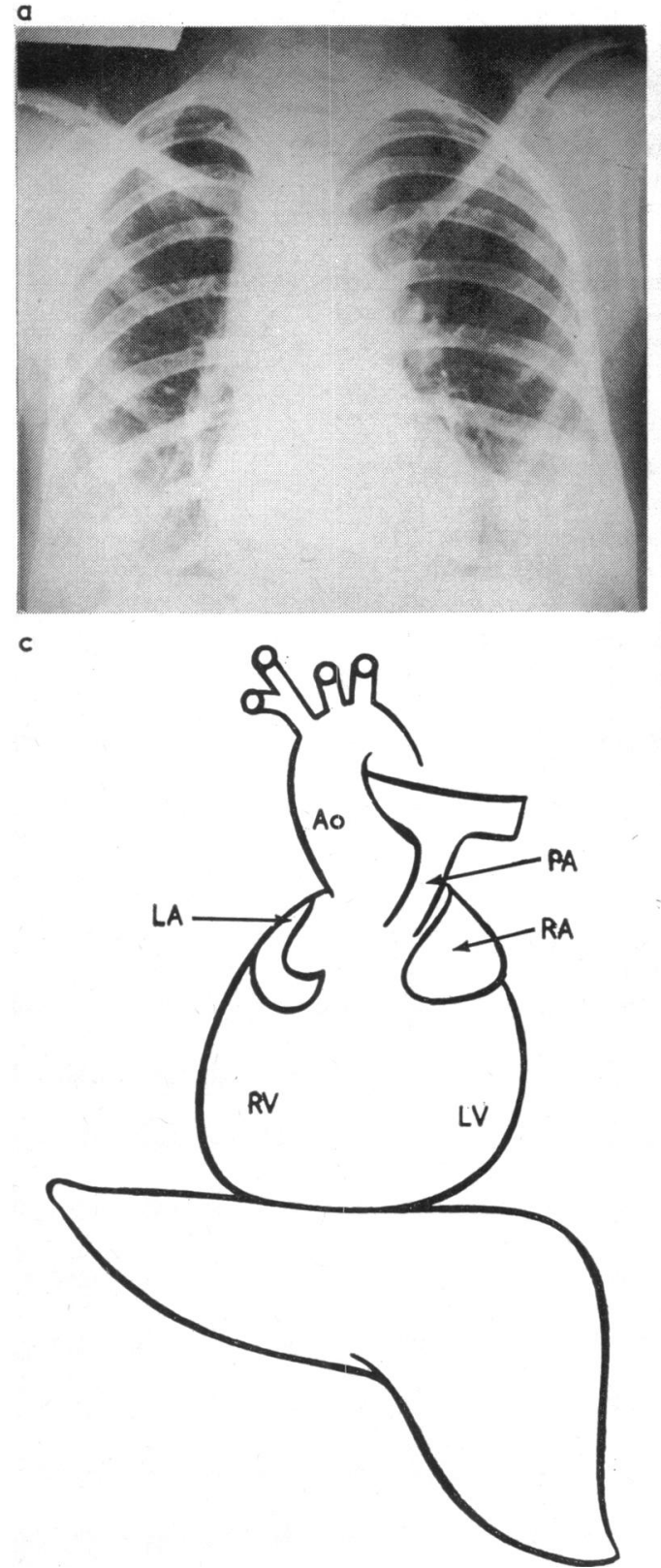

b

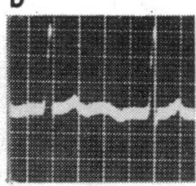

D1

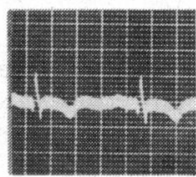

VR

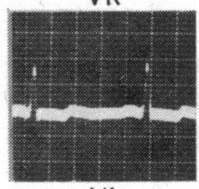

V1

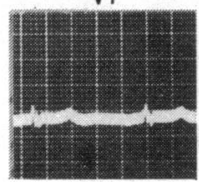

V4

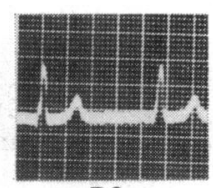

D2

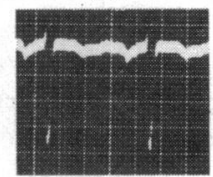

VL

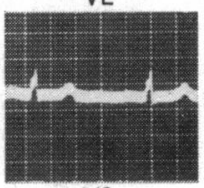

V2

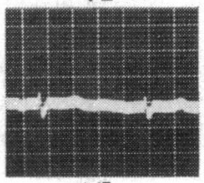

V5

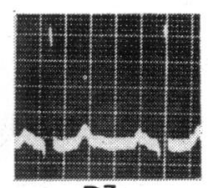

D3

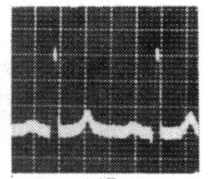

VF

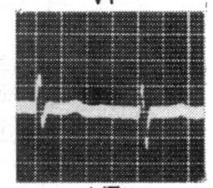

V3

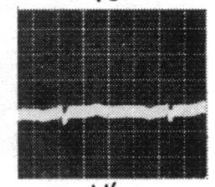

V6

d

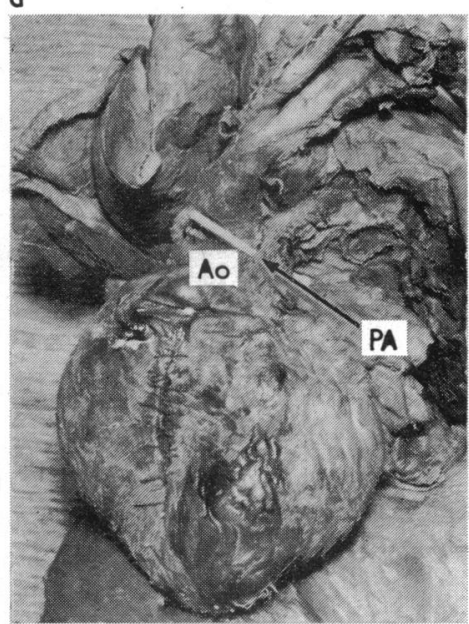


TABLE Catheterization data

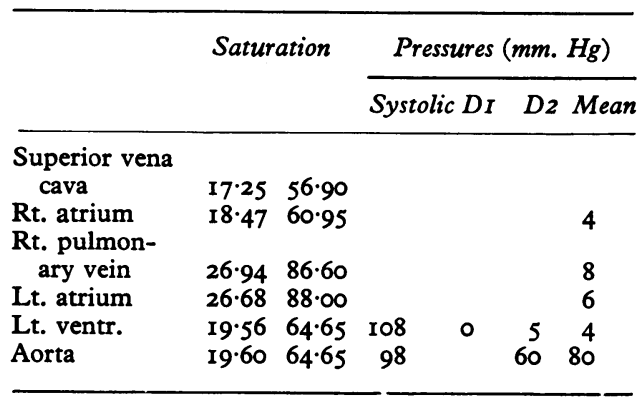

Hb $22.62 \mathrm{~g}$./100 ml., Hb capacity 30.31 vol. per cent, $\mathrm{O}_{2}$ consumption $224 \mathrm{ml}$. $/ \mathrm{min}$.

The electrocardiogram (Fig. Ib) showed inverted $P$ waves in lead $I$ and positive $P$ waves in VR. The sequence of the chest (praecordial) leads taken on the left side showed tall $R$ waves in VI and rs complexes in V6.

A tentative diagnosis was made of situs inversus, congenital heart disease with right-to-left shunt, and pulmonary stenosis. Cardiac catheterization and angiocardiography were performed (Table). The catheter entered the venous or anatomically right atrium placed on the left and ventricular chamber. The aorta filled from this ventricle and was clearly posterior with respect to the narrow pulmonary artery which filled simultaneously and crossed the aorta anteriorly, showing a normal relation of the great arteries, i.e. absence of transposition. It was concluded from these studies that there were large atrial and ventricular septal defects, an overriding aorta, and pulmonary infundibular stenosis. The diagnosis of situs inversus, dextrocardia, and possible tetralogy of Fallot with atrial septal defect or AV comunis was made, and operation was advised.

A left-sided subclavian pulmonary anastomosis was done. The patient developed ventricular fibrillation during the operation which was successfully treated. However, she died unexpectedly on the fourth post-operative day.

\section{Necropsy}

The viscera were placed as pertains to situs viscerum inversus; the cardiac apex was directed

FIG. 2 Internal view of the cardiac cavities of Case I with mirror-image dextrocardia and ventricular inversion without transposition of the great arteries. (a) The anatomical right atrium is placed on the left; notice the crista terminalis (CT), the pectineal muscles $(P M)$, the sinus portion (SP). An arrow points to the connexion of the inferior vena cava (IVC) with this atrium. This atrium connects with the inflow tract of a ventricle which exhibits a smooth interventricular septum in its upper two-thirds, characteristic of anatomical left ventricles. (b) The atrium placed on the right shows the smooth wall which characterizes the anatomical left atrium; notice the atrial septal defect $(A S D)$. This cavity connects with the inflow chamber of the anatomically right ventricle placed on the right. (c) The ventricle placed on the right shows the features of the anatomical right ventricle; notice the crista supraventricularis $(C S-V)$; a probe has been placed in front of it, within the stenotic infundibulum of the pulmonary artery $(P A)$. The interventricular septum is trabeculated. The aorta (Ao) emerges behind the crista, overriding the ventricular septum.
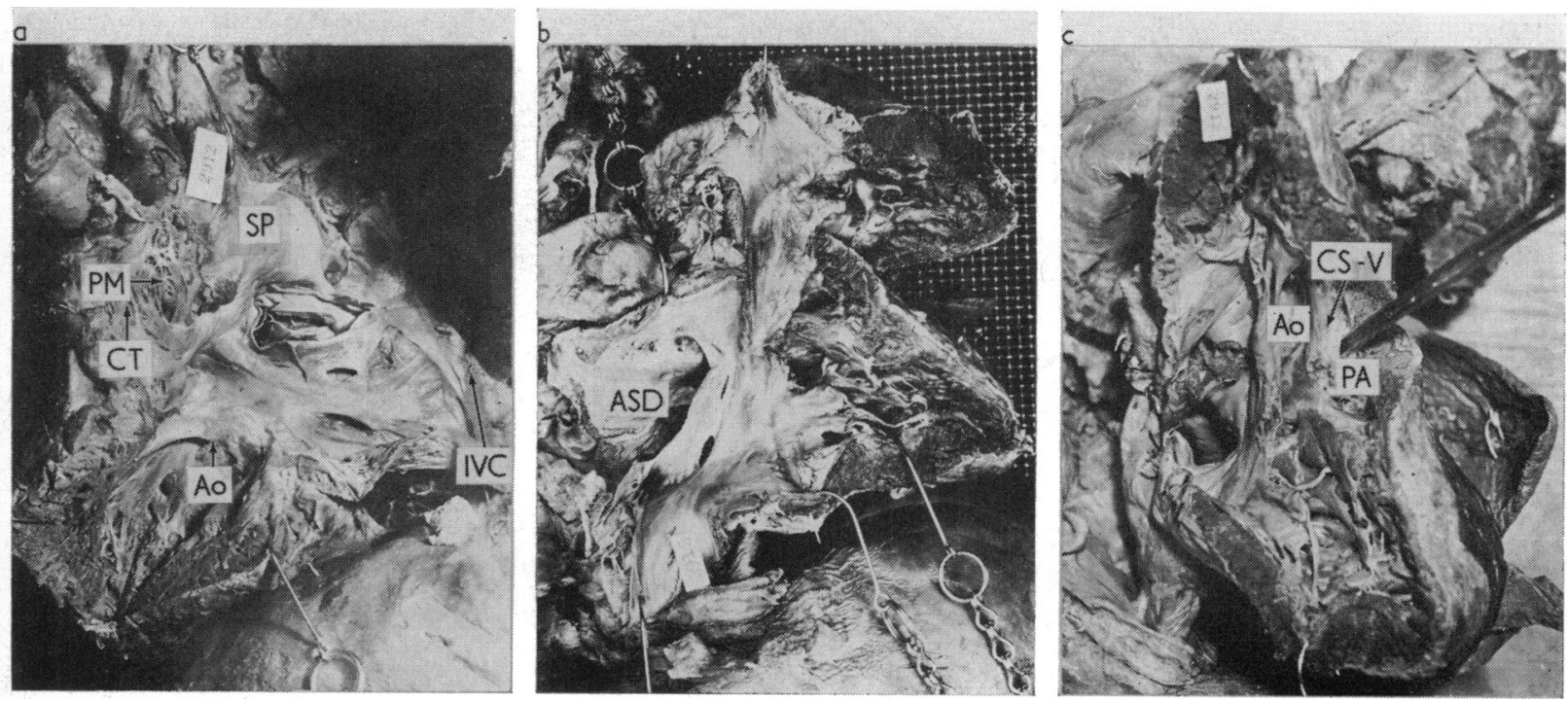
to the right. The pulmonary artery was of small calibre ( $\frac{1}{4}$ of the size of the aorta). It originated anteriorly with respect to the aorta crossing it from right to left and from the front to the back (Fig. IC and d). The aortic arch was located over the right bronchus (right-sided aortic arch). The left-sided atrial appendage was smooth and bulging as seen in anatomically right atrial appendages. The right-sided atrial appendage was small and irregular, as are anatomically left atrial appendages.

Internally the left-sided atrium had the anatomical features of a right atrium: there were two endocardial areas separated by the crista terminalis; the posterior part was smooth (sinus portion) and it connected with the inferior vena cava and the superior vena cava. The four pulmonary veins also entered this chamber; the anterior portion contained the pectineal muscles (Fig. 2a). This atrial chamber communicated through a stenotic valvular orifice protected by two valvular leaflets with a ventricle whose inner septal surface was smooth in its upper two-thirds and trabeculated in its lower third. This ventricle had two groups of papillary muscles and it lacked a crista supraventricularis. All of these features pertain to an anatomical left ventricle (Fig. 2a). The atrium placed on the right was smooth and it had the morphological features of the anatomical left atrium. There was a large interatrial septal defect of the fossa ovalis type with a fenestrated valve (Fig. 2b). This chamber communicated by means of an atrioventricular orifice having three valves with a right-sided ventricle which had a trabeculated septal surface. This ventricle had numerous trabeculae, an anterior papillary muscle, and the crista supraventricularis with its parietal and septal bands, which are the morphological features of an anatomical right ventricle (Fig. 2b and c). The pulmonary artery arose in front of the crista supraventricularis. It had infundibular and orificial stenoses (Fig. 2c). The aorta arose behind the crista overriding the ventricular septum; in the ventricular septum there was an interventricular septal defect of the middle basal type (Fig. 2d), i.e. absence of the pars membranacea.

Diagnosis Situs inversus; mirror-image dextrocardia; orificial stenosis of the left atrioventricular valve (mitral valve); ventricular inversion without transposition of the great vessels; interatrial septal defect; ventricular septal defect; total anomalous pulmonary venous connexion to the anatomical right atrium; orificial and infundibular stenosis in a hypoplastic pulmonary artery; dextroposition of the aorta; right-sided aortic arch.

Case 2 A 4-year-old girl, cyanotic from birth, began squatting at the age of 2 years. She was dyspnoeic on effort. Physical examination disclosed a small frail cyanotic child. The cardiac apex was felt at the $4^{\text {th }}$ left intercostal space. There wai a grade 2/4 systolic murmur at the third and fourth left intercostal spaces next to the sternal border; the second 'pulmonary' sound was soft. Blood pressure was 100/70 $\mathrm{mm}$. Hg. The liver was percussed on the left side.

The chest $x$-ray showed a grade $1 / 4$ cardiomegaly. The cardiac apex was directed to the left. The gastric bubble was visualized on the right side. The hilar vascular markings appeared almost normal. There was a prominent vascular segment on the right border of the heart which was thought to be the ascending aorta; it was slightly uncoiled. There was another prominent segment on the left cardiac border which was thought to be the pulmonary artery (Fig. 3a).

The electrocardiogram showed a negative $P$ wave in lead I which was suggestive of atrial inversion (situs inversus). There were rsR complexes in VR and V3R, and rS complexes in V6. The electrocardiogram was suggestive of right ventricular hypertrophy, and left atrial and probable right atrial enlargement (Fig. 3b).

The patient had convulsions following hypoxic episodes which left neurological sequelae. A cerebral abscess was postulated. This was confirmed and successfully treated surgically. Two months later the patient died during a severe hypoxic spell.

\section{Necropsy}

The viscera were arranged in situs inversus. The cardiac apex was directed to the left. The pulmonary artery was narrow (one-third the size of the aorta). It originated anteriorly with respect to the aorta crossing it obliquely from right to left and from the front to the back (Fig. $3 \mathrm{C}$ and d). The aortic arch overrode the right bronchus. The atrial appendage located on the left was smooth and bulging, the features usually seen in anatomically right atrial appendages. The atrial appendage on the right was small and irregular as seen in normal anatomically left atrial appendages. The internal aspect of the left-sided atrium had the anatomical features normally seen in right atria since it had two portions which were separated by the crista terminalis; the inner portion was smooth (sinus portion) and received the inferior and the superior vena cava; the outer portion had the pectineal muscles (Fig. 4a). There was no atrioventricular orifice in the floor of this atrium. The atrium placed on the right was smooth. It received the 4 pulmonary veins, which is the anatomical feature of normal left atria (Fig. 4b). The interatrial septum showed a defect of the fossa ovalis type (Fig. 4a). This atrial chamber communicated with the right-sided ventricle by a valvular orifice with three valves. This ventricle showed the crista supraventricularis and the anterior papillary muscle which are the normal morphological features of the anatomical right ventricle (Fig. 4b and c). The pulmonary artery, which had infundibular and valvular stenosis, originated in front of the crista. The aorta originated behind the crista (Fig. 4c). There were both hypertrophy and dilatation of this chamber. There was no left ventricular chamber. 
FIG. 3 Case 2 with laevocardia and ventricular inversion without transposition of the great vessels. (a) Chest film: this is a clear case of laevocardia, i.e. left-sided apex in the presence of a situs inversus. Notice in this case, also, the prominence of the ascending aorta (horizontal arrow) to the right and the prominent 'pulmonary' segment (vertical arrow) to the left. The hilar vascular markings are rather scant. (b) The electrocardiogram shows a negative $P$ wave in lead $I$ and VL, suggestive of dextrocardia. As in Case $I, V R$ shows a very positive complex which is indicative of right ventricular hypertrophy of a right-sided anatomical right ventricle (unusual position for a situs inversus, i.e. there is ventricular inversion). Finally, the sequence of the ventricular complexes in the praecordial leads is the expected sequence of normally placed ventricles in the presence of right ventricular hypertrophy. This arrangement of the ventricles is abnormal for the situs. (c) Diagrammatic representation showing the spatial relation of the great vessels, the cardiac cavities, the direction of the apex, and the position of the liver. $P A$, pulmonary artery; Ao, aorta; $L A$, anatomical left atrium; $R V$, anatomical right ventricle; $R A$, anatomical right atrium. $L V$ is the site which the left ventricle should have occupied since the specimen had no left ventricle. (d) External view of the heart, the great vessels, and the liver. $P A$, narrow pulmonary artery.

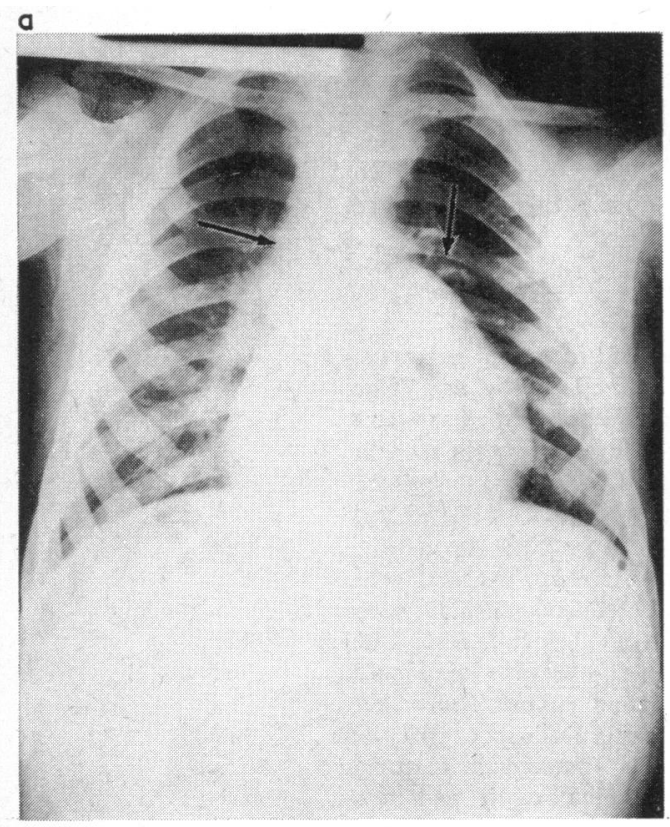

b

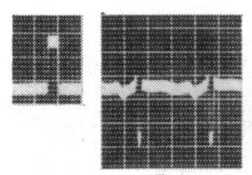

D1

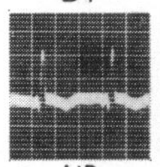

VR

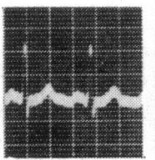

V3R

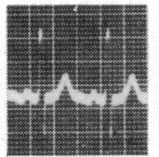

V1

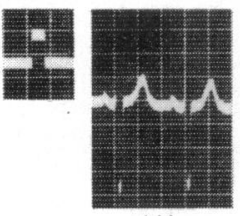

V4

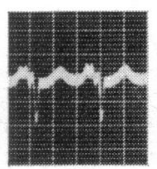

D2

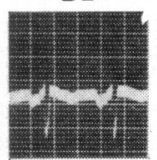

$\mathrm{VL}$

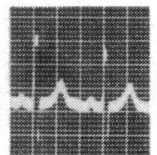

V2

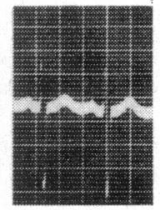

V5

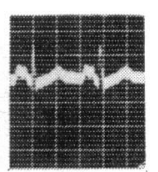

D3

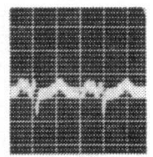

VF

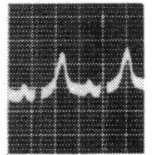

V3

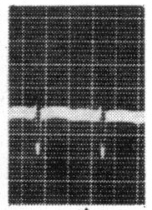

V6 $c$

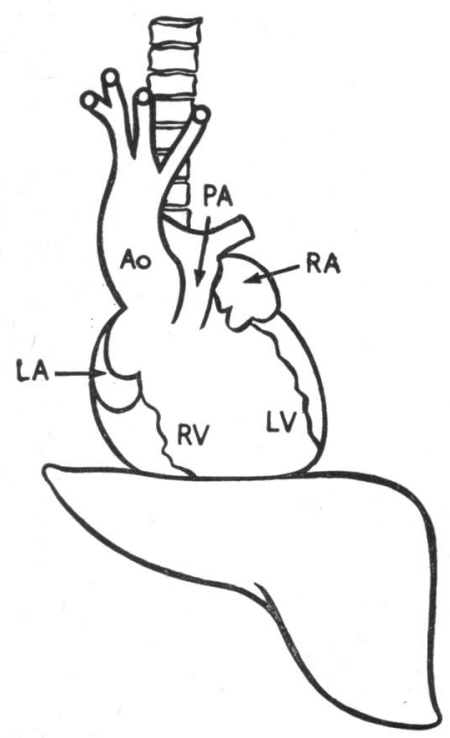

d

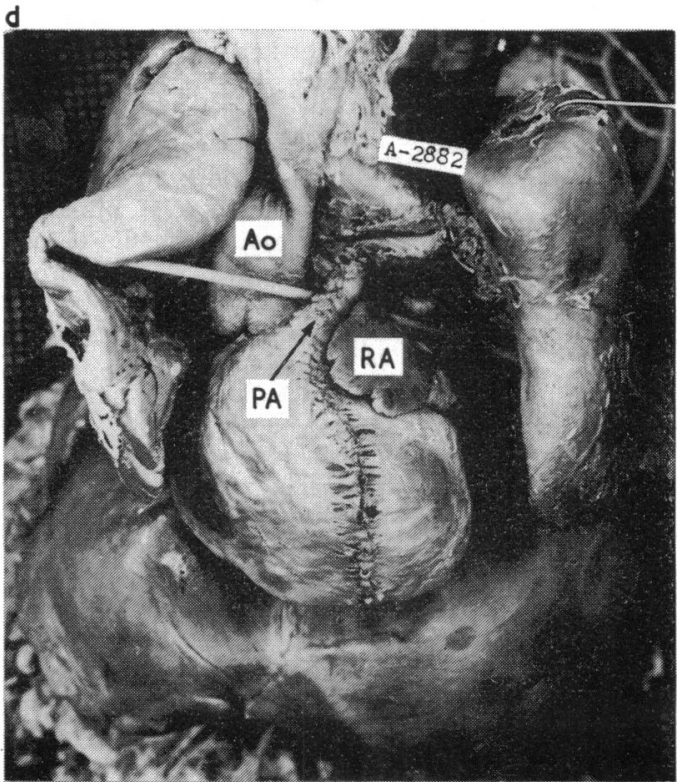



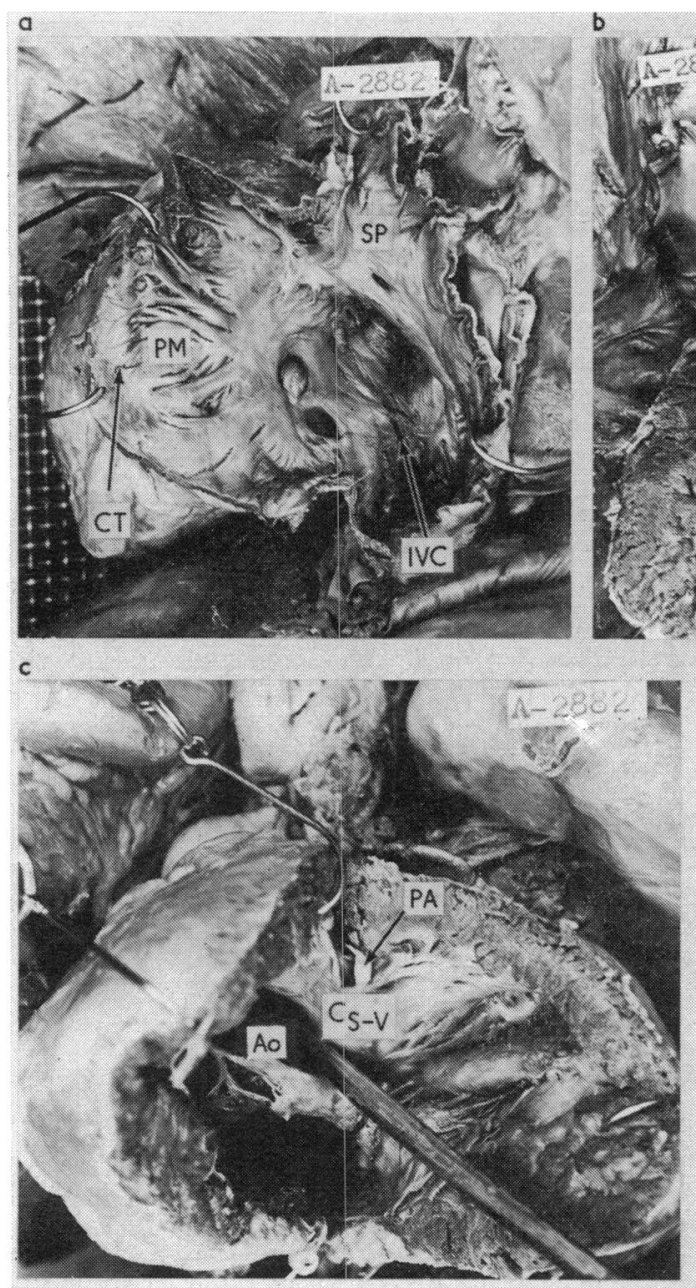

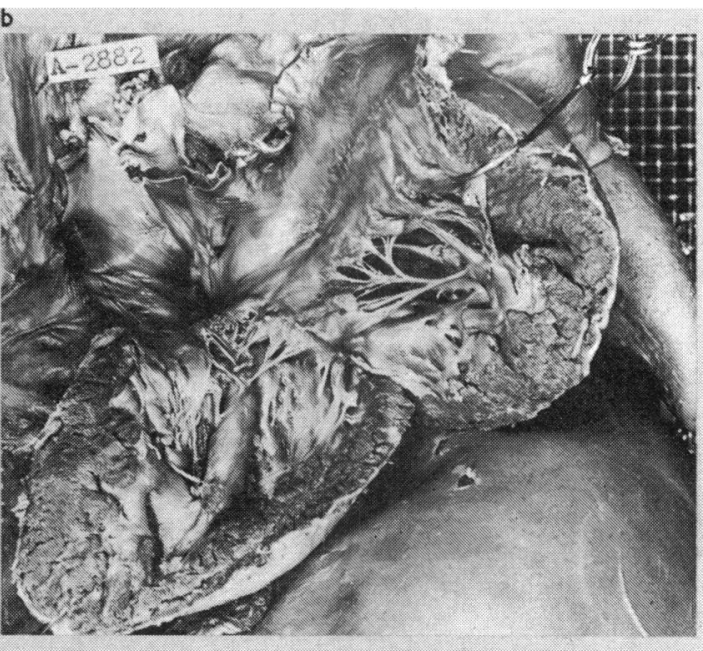

FIG. 4 Internal aspect of the cardiac chambers of Case 2 with laevocardia and ventricular inversion without transposition of the great vessels. (a)The anatomical right atrium is on the left; notice the crista terminalis $(C T)$, the pectineal muscles $(P M)$, the sinus portion $(S P)$. An arrow points to the connexion of the inferior vena cava (IVC) with this atrium. The atrioventricular orifice is atretic. (b) The atrium placed on the right shows smooth walls which are characteristic of the anatomical left atrium; it connects with the inflow chamber of the anatomical right ventricle. (c) The ventricle placed on the right shows the features of an anatomically right ventricle; the crista supraventricularis $(C S-V)$ in front of which the pulmonary artery $(P A)$ originates with infundibular stenosis; behind the crista is a probe placed within the orifice of the aorta (Ao); the interventricular septum is trabeculated.

Diagnosis Situs inversus, laevocardia, atresia of the left atrioventricular orifice (tricuspid); ventricular inversion without transposition of the great vessels; orificial and infundibular stenosis of the hypoplastic pulmonary artery; atrial septal defect.

\section{Discussion}

Anatomical outline The following anatomical outline seems justified in view of the need for classification of our cases and because there is considerable confusion concerning the anatomical concepts on visceral situs, on the position of the cardiac chambers, and of the vascular pedicle with respect to the situs. This confusion is readily apparent in the numerous names that are used in the nomenclature, most of which are erroneous
(Anselmi et al., 1963; Van Praagh and Van Praagh, 1967; Stanger et al., 1968). We will not analyse the anatomical concepts from the embryological standpoint as they have already been reported (de la Cruz and da Rocha, I956; de la Cruz et al., 1959, 1967).

A visceral situs is the spatial position of the viscera in relation to a system of symmetry, which in the case of the cordates is the bilateral symmetry system. The situs is established ontogenetically and phylogenetically before the heart appears. In the system of bilateral symmetry there are three types of situs: the solitus, the inversus, and heterotaxia.

The position of the atria is fixed for the specific situs; therefore there is never 'atrial inversion'; on the contrary, it is the position 
of the ventricles which may vary for a specific situs, and a malformation characterized by the disagreement between the ventricles and the viscero-atrial situs is designated with the name ventricular inversion (de la Cruz et al., 1967) (Fig. 5 and 6).

There are two types of ventricular inversion: one in situs solitus and one in situs inversus and both are accompanied always by inversion of the vascular pedicle, whatever the trunce-conal morphology may be (Fig. 5 C, G, H, I, and Fig. 6 C, G, H, I). The name inversion of the vascular pedicle is used for the mirror-image of any of the different trunco-conal morphologies of a specific situs without ventricular inversion (compare G, $H$, and $I$ with $D, E$, and $F$ in Fig. 5 and 6).

There are three fundamental trunco-conal morphologies for any situs whether they are associated with ventricular inversion or not (Fig. 5 and 6). (I) Without transposition of the great arteries. The pulmonary artery crosses in front of the aorta and consequently it arises from the anatomical right ventricle. The direction of the pulmonary artery indicates the position of the anatomically right ventricle. If this artery is directed from right to left, the anatomically right ventricle is placed on the right (Fig. 5D and 6B), and if the pulmonary artery is directed from left to right, the anatomically right ventricle is placed on the left (Fig. 5G and 6D). (2) With transposition of the great arteries. The aorta is anterior and parallel with respect to the pulmonary artery, and consequently it arises from the anatomically right ventricle, while the pulmonary artery arises from the anatomically left ventricle. The position of the transposed aorta with respect to the pulmonary artery indicates the location of the anatomically right ventricle. If the transposed aorta is on the right side of the pulmonary artery, the anatomically right ventricle is on the right (Fig. $5 \mathrm{E}$ and $6 \mathrm{H}$ ), and if the transposed aorta is on the left side of the pulmonary artery, the anatomically right ventricle is on the left (Fig. $5 \mathrm{H}$ and $6 \mathrm{E}$ ). (3) With persistence of the common truncus arteriosus. A single artery arises from the heart, and its direction points to the position of the anatomically right ventricle. If it is directed from right to left, the anatomical right ventricle is placed on the right side (Fig. 5F and 6I), and if it is directed from left to right, the anatomically right ventricle is on the left side (Fig. 5I and 6F).

\section{Situs solitus}

This is the normal spatial position of the viscera within a symmetry system in which

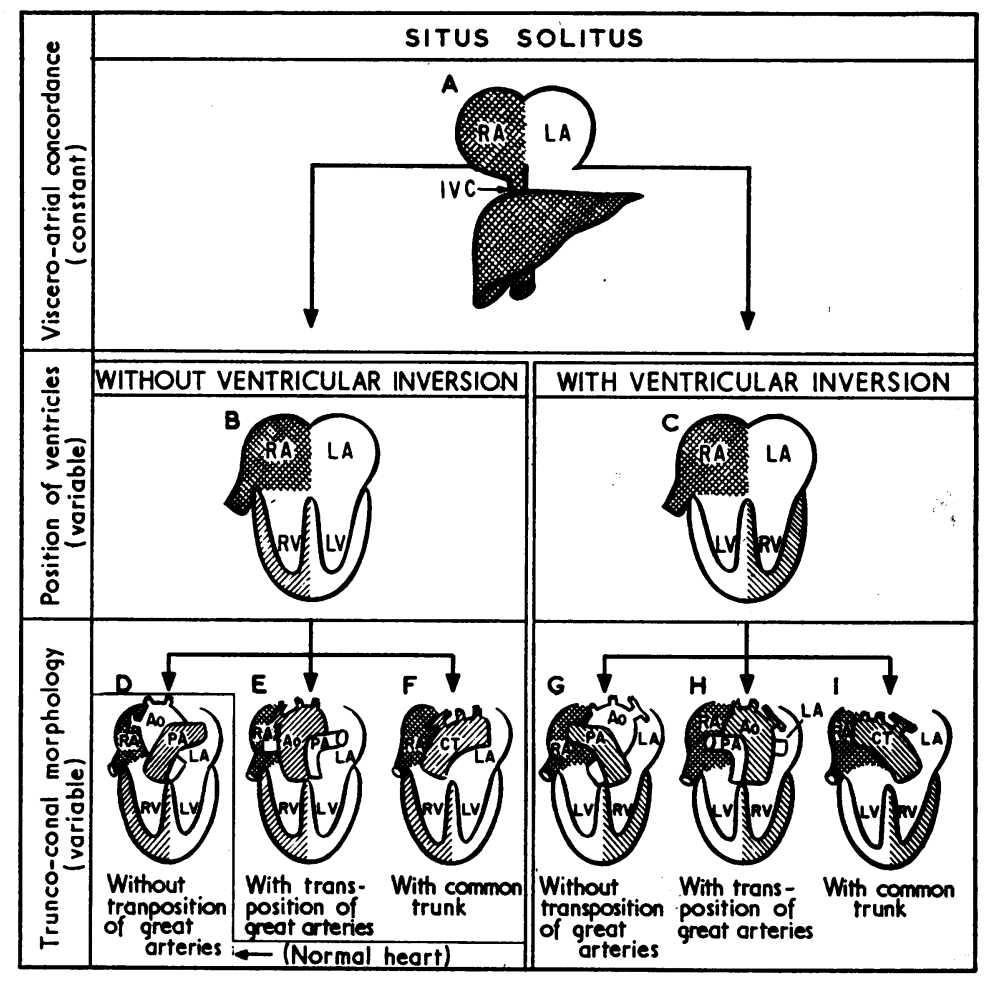

FIG. 5 Diagrams representing the relation of the atria with the ventricles and, also, the relation of the great vessels with each other and of these vessels with the cardiac chambers in situs solitus. $R A$, anatomically right atrium; $L A$, anatomically left atrium; IVC, inferior vena cava; $R V$, anatomically right ventricle; $L V$, anatomically left ventricle; Ao, aorta; $P A$, pulmonary artery; $C T$, common trunk.

the anatomically right structures are placed on the right and the anatomically left structures are placed on the left (Fig. 5A).

The normal heart of situs solitus is characterized by an anatomically right atrium and ventricle on the right side and an anatomically left atrium and ventricle on the left side. In other words, there is an atrioventricular concordance. The normal relation of the great vessels will then be such that the pulmonary artery is anterior and crosses the aorta from right to left and from the front to the back (Fig. 5D).

The three trunco-conal morphologies for the heart in situs solitus without ventricular inversion are: (I) Without transposition of the great vessels. The pulmonary artery crosses the aorta in front, and from right to left; therefore it arises from the anatomically right ventricle placed on the right. This 
morphology is the normal one for a normal heart in situs solitus (Fig. 5D). (2) With transposition of the great vessels. The aorta is anterior, parallel to, and placed on the right of the pulmonary artery; therefore it arises from the anatomically right ventricle placed on the right (Fig. $5 \mathrm{E}$ ). (3) With persistence of the common truncus arteriosus. This vessel is directed from right to left and indicates the right-sided position of the anatomically right ventricle (Fig. $5 \mathrm{~F}$ ).

In situs solitus, ventricular inversion is characterized because the anatomically left ventricle is on the right and it receives blood from the anatomically right atrium placed on the right (venous atrium), and the anatomically right ventricle is placed on the left, and it receives blood from the anatomically left atrium placed on the left (arterial atrium) (Fig. 5C).

The three trunco-conal morphologies for the heart in situs solitus with ventricular inversion are as follows: (I) Without transposition of the great vessels, in which the pulmonary artery crosses in front of the aorta from left to right and from the front to the back; therefore it arises from the anatomically right ventricle placed on the left (Fig. 5G) and it constitutes the mirror-image of the vascular pedicle of a normal heart in situs solitus (inversion of the vascular pedicle) (compare $G$ with $D$ in Fig. 5). This cardiopathy functions as a transposition of the great vessels without actually being one anatomically, because the great vessels are not related to each other nor with the ventricles as in a true transposition of the great vessels (compare $G$ with $E$ in Fig. 5). Therefore, the designation 'clinical transposition' (Stanger et al., 1968) for this cardiopathy is erroneous because it is not a transposition of the great vessels and because it ignores the basic malformation which is a ventricular inversion. For this reason it is best to designate it as ventricular inversion without transposition of the great vessels (de la Cruz et al., 1967). (2) With transposition of the great vessels, the aorta is anterior, parallel, and placed to the left of the pulmonary artery; therefore it arises from the anatomically right ventricle placed on the left (Fig. $5 \mathrm{H}$ ). This malformation behaves from a haemodynamic standpoint as a normal heart, and for this reason it is currently designated as 'corrected transposition of the great vessels' (Walmsley, 1931; Abbott, 1936; Liebow and McFarland, 194I; de la Cruz et al., 1959, 1962; Van Praagh et al., 1964). This designation again is erroneous, since there is no anatomical correction, because the great vessels are

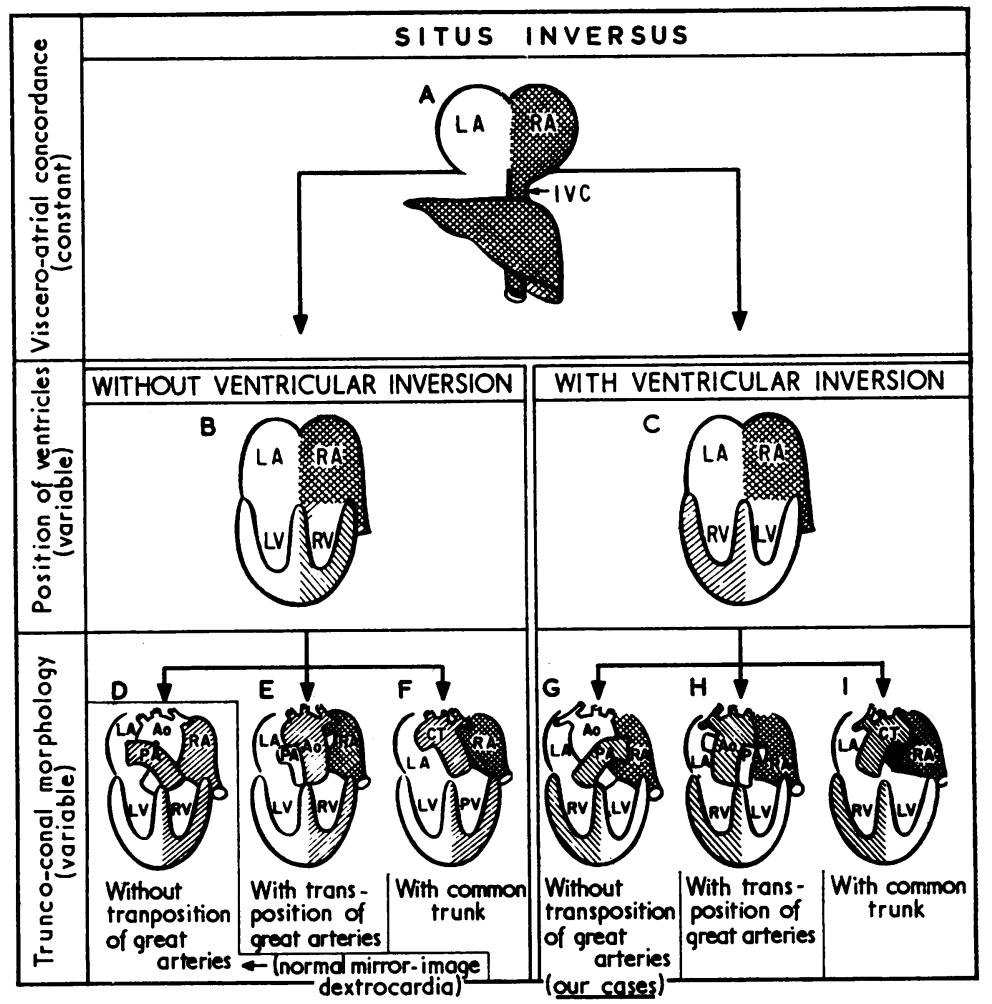

FIG. 6 Diagrams representing the relation of the atria with the ventricles and, also, the relation of the great vessels with each other and of these vessels with the cardiac chambers, in situs inversus. $R A$, anatomically right atrium; $L A$, anatomically left atrium; IVC, inferior vena cava; $R V$, anatomically right ventricle; $L V$, anatomically left ventricle; Ao, aorta; $P A$, pulmonary artery; $C T$, common trunk.

related with each other and with their respective ventricles in the fashion of transposition of the great vessels, and because this designation ignores the fact that ventricular inversion is the basic malformation in this cardiopathy (compare $\mathrm{H}$ with $\mathrm{E}$ in Fig. 5). (3) With persistence of the common truncus arteriosus. This artery is directed from left to right and it indicates the left position of the anatomically right ventricle (Fig. 5I).

In situs solitus, there are two positions of the apex: in one, it is directed to the left and the heart is normally placed, and in the other one the apex is directed to the right, i.e. constituting a case of dextroversion or dextrorotation.

Situs inversus

This is the designation used for the spatial 
disposition of the viscera in which the anatomically right structures are placed on the left and the anatomically left structures are placed on the right, thus constituting the mirror-image of situs solitus (Fig. 6A).

The normal heart of situs inversus (mirrorimage dextrocardia) is characterized by the fact that the anatomically right atrium and ventricle are on the left and the anatomically left atrium and ventricle are on the right. There is also, therefore, an atrioventricular concordance. The normal relation of the great vessels is such that the pulmonary artery is anterior and it crosses in front of the aorta from left to right and from the front to the back (Fig. 6D).

The three trunco-conal morphologies for the heart in situs inversus without ventricular inversion are: (I) Without transposition of the great vessels in which the pulmonary artery crosses the aorta in front and from left to right, therefore arising from the anatomically right ventricle placed on the left. This morphology corresponds to the normal heart in situs inversus (mirror-image dextrocardia) and the great vessels are not inverted for this type of situs (Fig. 6D). (2) With transposition of the great vessels in which the aorta is anterior, parallel, and placed to the left of the pulmonary artery; therefore it arises from the anatomically right ventricle placed on the left (Fig. 6E). (3) With persistence of the truncus arteriosus. This artery is directed from left to right and it indicates the leftsided position of the anatomically right ventricle (Fig. 6F).

In situs inversus, ventricular inversion is characterized by the fact that the anatomically right ventricle is placed on the right and it receives blood from the anatomically left atrium placed on the right (arterial atrium), and the anatomically left ventricle is placed on the left and it receives blood from the anatomically right atrium placed on the left (venous atrium) (Fig. 6C).

The atria agree with the situs since they maintain the position that they have in mirror-image dextrocardia, i.e. the normal heart for situs inversus (compare $C$ with $D$ in Fig. 6), whereas the ventricles are inverted because they have a completely abnormal position for a mirror-image dextrocardia (compare $\mathrm{C}$ with D in Fig. 6), in spite of the fact that they have the same position as a normal heart for situs solitus (compare C in Fig. 6 with D in Fig. 5).

The three trunco-conal morphologies for the heart in situs inversus with ventricular inversion are: (I) Without transposition of the great arteries, in which the pulmonary artery crosses in front of the aorta, from right to left and from the front to the back; therefore it arises from the anatomically right ventricle placed on the right (Fig. 6G). These arteries are inverted for a mirror-image dextrocardia (compare $G$ with D in Fig. 6), despite the fact that they have the relation of the vascular pedicle of a normal heart in situs solitus (compare $G$ in Fig. 6 with $D$ in Fig. 5). This cardiopathy functions as a transposition of the great vessels, even though it is not one from the anatomical standpoint. Therefore the designation 'clinical transposition' (Stanger et al., 1968) is also erroneous because it is not a transposition of the great arteries and because it ignores the basic malformation which again is ventricular inversion (compare $\mathrm{G}$ with $\mathrm{E}$ in Fig. 6). For this reason we call it ventricular inversion without transposition of the great arteries in situs inversus (de la Cruz et al., 1967). (2) With transposition of the great arteries, the aorta is anterior, parallel, and placed on the right side of the pulmonary artery; therefore it arises from the anatomically right ventricle placed on the right (Fig. $6 \mathrm{H})$. This malformation behaves haemodynamically as a normal heart and it is currently designated as 'corrected transposition of the great arteries' (Walmsley, I93I; Abbott, 1936; Liebow and McFarland, I94I; de la Cruz et al., 1959, I962; Van Praagh et al., 1964). This designation is also erroneous since the anatomical image is that of transposition of the great arteries with ventricular inversion. (3) With persistence of the common truncus arteriosus. This artery is directed from right to left and it indicates the rightsided position of the anatomically right ventricle (Fig. 6I). In situs inversus there are also two positions of the apex: it is either on the right, in which case there is a mirrorimage dextrocardia, or the apex is directed to the left in which case it is a laevocardia.

The cases under discussion are examples of ventricular inversion without transposition of the great arteries in situs inversus (Fig. $6 \mathrm{G})$, one of them with a mirror-image dextrocardia and the other with a laevocardia. These cases should not be called complete clinical transposition in situs inversus, because the relation of the great vessels between themselves and with respect to the ventricles does not correspond to the anatomical picture of transposition and because it would ignore the fact that the basic malformation is ventricular inversion. Other authors (Stanger et al., 1968) would perhaps maintain that the position of the ventricles and the relation of the vascular pedicle of our cases are normal for situs inversus with ventricular inversion. 
We differ from this view because the normal position of the ventricles and the normal relation of the vascular pedicle for a situs inversus is that seen in mirror-image dextrocardia (normal heart in situs inversus) (compare $G$ with $D$ in Fig. 6).

In both of our cases there is unequal partition of the truncus conus at the expense of the pulmonary artery associated with dextroposition of the aorta (lateroposition) (de la Cruz and da Rocha, 1956). The case with laevocardia also shows atresia of the left atrioventricular orifice, which is responsible for the absence of the anatomically left ventricle.

Clinical analysis This malformation is extremely rare; perhaps no more than four cases have been reported to date (Lev and Rowlatt, I96I ; Van Praagh and Van Praagh, 1966; Martínez Picó and Muñoz, 1967) in situs solitus. To our knowledge these two cases with situs inversus may be the first to be reported in which there is 'isolated ventricular inversion' (Van Praagh and Van Praagh, I966), i.e. absence of transposition of the great arteries.

In the case with mirror-image dextrocardia the diagnosis of tetralogy of Fallot was made on the basis of a severely cyanotic and incapacitating malformation, mainly from the catheterization findings (see below). Indeed the radiological picture did not suggest the diagnosis.

In the case with laevocardia the diagnosis of 'corrected transposition of the great vessels' was postulated initially on the basis of our experience and that of others (Lev and Rowlatt, 196I), according to which laevocardia is frequently associated with transposition of the great arteries and ventricular inversion. The diagnosis of septal defects and pulmonary stenosis was also postulated in this case, but unfortunately no specialized studies could be made due to the severity of the patient's condition. Though this patient's heart had no left ventricle it is apparent that the left $A V$ valve was atretic while the right one was the tricuspid (three leaflets). Furthermore, the single ventricle was unquestionably anatomically right.

In both instances there were two common physiopathological features: (i) a venousarterial shunt across the septal defects; (ii) a decreased pulmonary flow.

The analysis of Fig. 7A, a, B, b, shows that the course of the blood in these malformations, independently of the septal defects, of the intrinsic anatomy of the great arteries, and of the situs, is as abnormal in ventri-

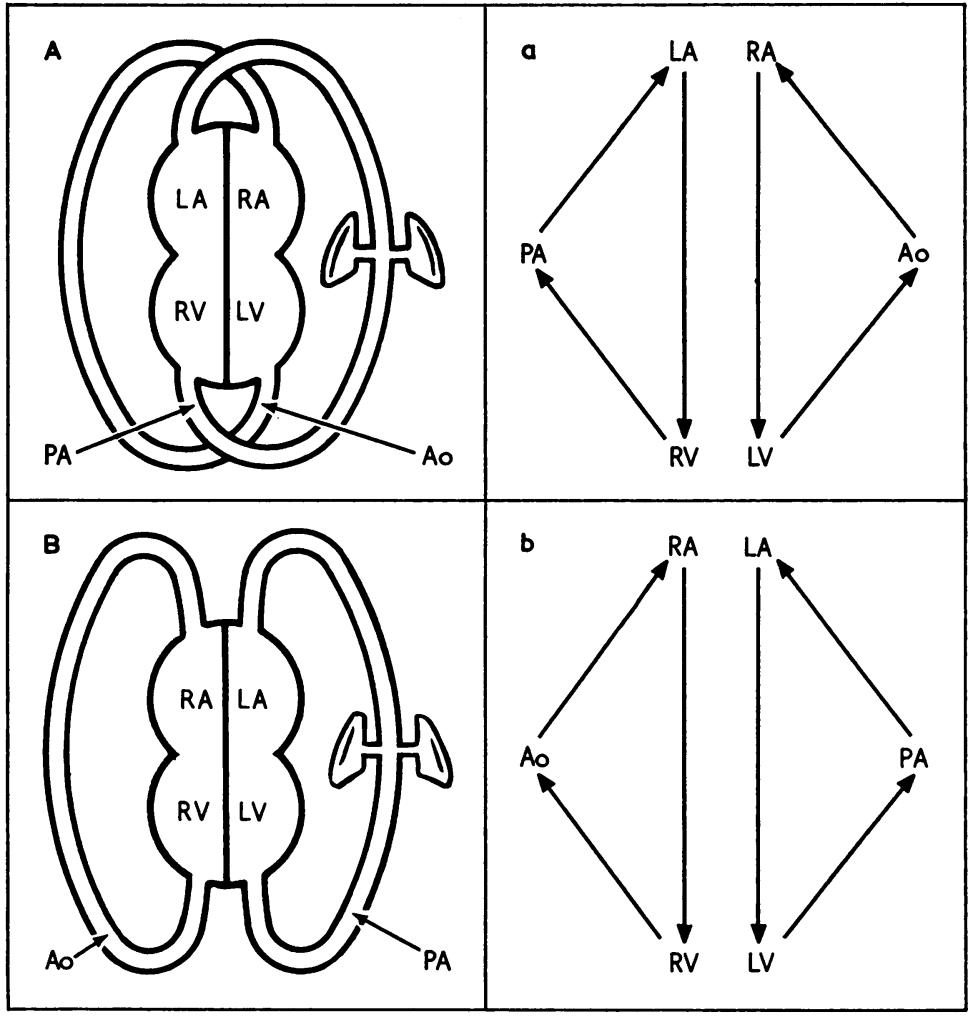

FIG. $7 \quad A$, and a, are diagrams representing the arrangement of the circulatory pattern in cases of ventricular inversion with normally arranged great vessels reproducing the haemodynamic pattern of ordinary complete transposition of the great vessels (diagrams $B$, and $b$ ).

cular inversion with normal relation of the great arteries (without transposition of the great arteries) (Fig. $7 \mathrm{~A}$ and $\mathrm{a}$ ) as in ordinary complete transposition of the great arteries (Fig. $7 \mathrm{~B}$ and $b$ ), thus rendering the haemodynamic picture in both conditions somewhat similar. In other words, in the malformation under discussion, blood that has been oxygenated in the lungs returns to the anatomically left atrium and enters the anatomically right ventricle from which it is redirected to the lung by way of the pulmonary artery. In the opposite circuit, the blood from the left ventricle enters the aorta and returns to the anatomically right atrium through the vena cava without having come in contact with the lungs. This haemodynamic arrangement has been described as 'physiologic transposition of the circulation with normal aortopulmonary relationship' (Martínez Picó and Muñoz, 1967). 
Radiology In Case I the prominent segment on the left cardiac border which we know from the specimen to be, in part, the pulmonary segment, is unusual for a case with clear lung fields and pulmonary stenosis (see Fig. Ia). This prominent segment was formed by the combination of the pulmonary artery and a large anatomically right atrial appendage placed on the left side (see also Fig. 6G).

The case with situs inversus and laevocardia (Case 2) had a cardiac contour which suggested initially the diagnosis of transposition of the great vessels associated with ventricular inversion (Fig. 3a). The prominent segment pointed by the vertical arrow in this figure was erroneously taken to be the origin of the aorta, emerging from the left border of the heart. This prominent segment was also formed by the combination of the pulmonary artery, and the anatomically right atrial appendage placed on the left side.

These two structures coincided in the space existing between the left border of the aorta and the left border of the heart formed by the anatomically left ventricle (see Fig. Ic, $3 c$, and $6 \mathrm{G}$ ).

This prominent segment on the left cardiac profile has been a useful diagnostic element in ventricular inversion with transposition of the great vessels in situs solitus where it corresponds to the initial portion of the ascending aorta. This was not the case in these patients.

Another feature of this cardiac contour was the prominent ascending aorta to the right (Fig. Ia and 3a). This seems to be due to the dextroposition of the aorta and also to the right-sided aortic arch which both cases had.

Electrocardiography In both cases the diagnosis of situs inversus was substantiated by the presence of a negative $P$ wave in leads $I$ and VL. VL had the aspect of a normal VR and vice versa, as far as the $P$ wave was concerned (Fig. Ib and $3 \mathrm{~b}$ ). In contrast with this, the morphology of the ventricular complexes in the praecordial leads VI to V6 had a sequence which suggested that the activation of the heart was the mirror-image of normal for a situs inversus, and suggestive of ventricular inversion with right ventricular enlargement; thence the Rs type complexes in VI and rS type complexes in V6. Such morphologies seem to be compatible with extreme clockwise rotation of the ventricular septum. The specimens show that the anatomically right ventricle is the over- loaded one. Furthermore, in the case of laevocardia, there was no left ventricle. For this reason a tentative diagnosis in this case had been tricuspid atresia in situs inversus.

Specialized studies From the catheterization data of our first case it appears that the left-sided (anatomically left) ventricle could not be entered. The reason for this was that there was a stenotic left atrioventricular valve. However, the aorta originated partly from this ventricle, overriding the septum, and it was entered with the catheter from the opposite ventricle. A very low wedge pressure in a pulmonary vein $(7.7 \mathrm{~mm}$. $\mathrm{Hg})$ was indicative of a low pulmonary artery pressure and, by inference, of pulmonary stenosis.

Injection of radiopaque material from the right-sided and anatomically right ventricle into the overriding aorta simultaneously opacified the pulmonary artery. As seen in Fig. Id, the arrangement of the great vessels is not in a parallel fashion. On the contrary, the aorta is a posterior vessel and the narrow pulmonary artery crosses it anteriorly. These data were found compatible with a tetralogy of Fallot.

Though a higher arterial oxygen saturation was found in the anatomically left atrium (right-sided), than in the anatomically right atrium (left-sided), the specimen showed that the four pulmonary veins entered the latter chamber. The only explanation for this (aside from the fact that considerable complexity of a case with situs inversus renders catheterization difficult) is a preferential flow of blood from the pulmonary veins into the opposite atrium across a large atrial septal defect.

In the presence of pulmonary ischaemia, a surgical anastomosis between a systemic vessel and the pulmonary artery seemed justified in both patients, inasmuch as patients with this malformation, as in many with pulmonary stenosis, benefit from an increase of flow to the lungs. In one patient (the one erroneously thought to be a tetralogy of Fallot) the anastomosis was performed and was apparently successful; unexpected death from an unidentified cause was probably not due to the new haemodynamic pattern created by the procedure.

\section{References}

Abbott, M. E. (1936). Atlas of Congenital Cardiac Disease. American Heart Association, New York.

Anselmi, G., Muñoz, S., Machado, I., Blanco, P., and Espino-Vela, J. (I963). Complex cardiovascular malformations associated with the corrected type of transposition of the great vessels. American Heart fournal, 66, 614. 
de la Cruz, M. V., Anselmi, G., Cisneros, F., Reinhold, M., Portillo, B., and Espino-Vela, J. (1959). An embryological explanation for the corrected transposition of the great vessels: additional description of the main anatomic features of this malformation and its varieties. American Heart Fournal, 57, ro4.

- , and da Rocha, J. P. (1956). An ontogenetic theory for the explanation of congenital malformations involving the truncus and conus. American Heart fournal, 51, 782.

- Espino-Vela, J., Attie, F., and Muñoz-Castellanos, L. (1967). An embryologic theory for ventricular inversions and their classification. American Heart fournal, 73, 777.

, Polansky, B. J., and Navarro-López, F. (1962). The diagnosis of corrected transposition of the great vessels. British Heart fournal, 24, 483.

Lev, M., and Rowlatt, U. F. (196I). The pathologic anatomy of mixed levocardia. A review of 13 cases of atrial or ventricular inversion with or without corrected transposition. American fournal of Cardiology, 8, 216.

Liebow, A. A., and McFarland, W. (I94I). 'Corrected transposition' and persistent rudimentary 'right aorta' as evidence in support of Spitzer's theory. Archives of Pathology, 32, 356.

Martínez-Picó, A., and Muñoz, A. (1967). Inversión ventricular; transposición fisiológica de la circulación y relación aorto-pulmonar normal. Boletín Asociación Médica de Puerto Rico, 59, 26.

Stanger, P., Benassi, R. C., Korns, M. E., Jue, K. L., and Edwards, J. E. (1968). Diagrammatic portrayal of variations in cardiac structure. Reference to transposition, dextrocardia and the concept of four normal hearts. Circulation, 37, Suppl. IV.

Van Praagh, R., and Van Praagh, S. (I966). Isolated ventricular inversion. A consideration of the morphogenesis, definition and diagnosis of nontransposed great arteries. American fournal of Cardiology, 17, 395.

- , and - (1967). Anatomically corrected transposition of the great arteries. British Heart fournal, 29, 112.

, - Vlad, P., and Keith, J. D. (1964). Anatomic types of congenital dextrocardia. Diagnostic and embryologic implications. American fournal of Cardiology, 13, 510.

Walmsley, T. (I93I). Transposition of the ventricles and the arterial stems. Fournal of Anatomy, 65, 528. 